\title{
Indian Courts and Social Change: A Case Study of the Doctrine of Informed Consent in Medical Law and Ethics
}

\author{
Dharmendra Chatur*
}

\section{Abstract}

The doctrine of informed consent in medical law and ethics has a strong grounding in the principle of bodily autonomy and self-determination of human beings. This emphasis on the freedom of every individual to decide what is best for his/her body and health has led to several controversies in the area of medical law and ethics in India and abroad, especially in the United Kingdom. Being a legal and ethical doctrine, 'informed consent' has been discarded, accepted, modified and emulated by various judgments of courts. This paper will examine the ingenuity of courts in bringing about social change by upholding patient autonomy and adopting the doctrine of informed consent in the UK. However, this doctrine has been rejected by the Indian Supreme Court, citing the reason that Indian citizens are unprepared and illequipped to understand the complexities of medical treatment and procedures. This view, in the author's opinion, is a missed opportunity for the Indian Supreme Court to bring about social change by upholding patient rights and autonomy.

Keywords: Doctrine of informed consent; Social change; Courts in India; Bodily autonomy; Law and ethics introduction

*5th year BA, LLB (Hons.), School of Law, Christ University and Research Assistant, Centre for Law and Policy Research, Bangalore; dharmendra.chatur@law.christuniversity.in 
That the body of every person is inviolate has been recognized as a fundamental principle (Re F (Mental Patient: Sterilization), 1990). Directly flowing from this is the duty to respect the physical integrity of that person which can be legally violated only with the valid consent of that person. Medical treatment, diagnosis, examination etc. requires that the doctor touch or physically contact the patient. However, a legal requirement exists which mandates that a patient with capacity must give consent before being subject to any medical procedure. This is a reflection and reaffirmation of the principle of patient autonomy or right of selfdetermination of a person(Airedale NHS Trust $v$ Bland, 1993; see Schloendorff $v$ Society of New York Hospital, 1914, p. 126: “every human being of adult years and sound mind has a right to determine what shall be done with his own body"). For consent to treatment to be legally valid, three elements must be present (Grubb, Liang, \& McHale, 2010, ๆ 8.68):

1. consent must be given by a person with capacity;

2. consent must be based upon information about risks; and

3. consent must be voluntary.

It is with the second element of a valid consent that the doctrine of 'informed consent' relates to. The doctrine was first formulated in the United States in 1971 in the case of Canterbury $v$ Spence. ${ }^{1}$ In this case, the doctrine was formulated to impose a duty on physicians to disclose all material risks. Slowly, this doctrine in its various manifestations came to be recognized in the United Kingdom (Sidaway $v$ Board of Governors of the Bethlem Royal Hospital and the Maudsley Hospital and others, 1985; and later comprehensively adopted in Chester $v$ Afshar, 2004) and to a certain extent in India.

\section{Definition of Informed Consent}

Consent is considered fully informed when a capacitated (or "competent") patient or research subject to whom full disclosures have been made and who understands fully all that has been disclosed, voluntarily consents to treatment or participation on this

${ }^{1} 464$ F $2 d 772$ (1972). 
basis (Eyal, 2012). This definition though is not very helpful in understanding the constituents of the doctrine. The interpretation of informed consent has turned on various factors such as rick disclosure, nature of risk, and extent of disclosure and so on. Though it is agreed that certain minimum standards of informed consent must exist, it is generally the case that medical ethics places a higher standard of compliance than medical law (Miola, 2007). The doctrine of informed consent therefore demands recognition of a patient's right to be informed of the risks inherent in medical treatment, side effects and alternatives to the proposed treatment(Cane \& Conaghan, 2008, p. 202).

Informed consent is important both in medical procedures as well as medical research. This paper will focus only on the former, however, where necessary, references to the latter will be made. This paper will examine the development of the doctrine of informed consent in both the UK and India. In Part I, the development of the case law from Sidaway to Chester and beyond will analysed. This part will conclude with the current legal and ethical position relating to informed consent in the UK. In Part II, the law in India relating to consent and specifically informed consent will be analysed. Also, an effort will be made to place the applicability and development of the doctrine in a statutory law setting. Part III Conclusion will contain an analysis into whether informed consent and mechanisms put in place to effectuate it actually enhance patient choice and autonomy and to that end if they validate the existence of such a doctrine. Especially the need for a doctrine of informed consent in India will be discussed, with its myriad insufficiencies in the health and medical care sector and with the lessons that must be learnt from experiences with the doctrine in other countries. Finally, the author will comment as to how the courts can play a positive role in bringing about social change by adopting the doctrine of informed consent.

\section{Development of the Doctrine of Informed Consent}

\section{Philosophical grounding of the doctrine}

The main debates surrounding informed consent deal with principles such as protection, autonomy, prevention of abusive 
conduct, trust, self-ownership, non-domination, and personal integrity (Eyal, 2012).

However, Peter H Schuck identifies informed consent to be of three variations: informed consent 'in books', 'in mind' and 'in action' (Schuck, Rethinking Informed Consent, 1994, p. 903). The first is what the courts and legislatures deem informed consent to be, the second is what a doctor or practitioner believes to be binding in him as a requirement of informed consent and the third is what in reality is practiced as informed consent. Schuck makes it clear that there exist considerable gaps between the three and especially in the academic opinion about informed consent and its true applicability and scope. Schuck proposes that informed consent must be reconsidered to make it more cost-effective, to ensure that risks are communicated with a comparative cost-benefit analysis and finally that any perception of risks is dependent on the context a particular individual or society places it in (Schuck, p. 906; for a similar argument, see Manson \& O’Neill, 2007, pp. 68-96).

The point of consent procedures is to limit deception and coercion, they should be designed to give patients and others control over the amount of information they receive an opportunity to rescind consent already given (O'Neill, 2003, pp. 4-7; for a moral point-ofview of informed consent, see Pattinson, 2006, p. 116).

\section{United Kingdom: From bolam and sidaway to chester and beyond}

The development of a duty to disclose risks to patients becoming a part of the doctrine of informed consent began with the Bolam case (Bolam v Friern Hospital Management Committee, 1957).This case declined any application of the informed consent doctrine in the UK and instead reaffirmed the paternalistic attitude that courts had towards the medical profession. The approach was more on the lines of whether the standard of risk disclosure required of doctors was an 'accepted medical practice': that a doctor would not be negligent if he failed to disclose a risk and which failure was endorsed by a responsible body of medical opinion (Stauch, Wheat, \& Tingle, 2006, p. 139).

The first case after Bolam, where a classic informed consent/risk disclosure scenario was examined was the Sidaway case (Sidaway $v$ Board of Governors of the Bethlem Royal Hospital and the Maudsley 
Hospital and others, 1985). The decision in this case turned on how a risk could be defined to be material so as to make it necessary to be disclosed.2In Sidaway, therefore, the decision of disclosure of risk was primarily left to the clinical judgment of the doctors rather than respecting the autonomy of the patient. ${ }^{3}$ One reason why this might have been the decision is because Sidaway related to the provision of unsought information. The Sidaway judgment came to be followed in two subsequent decisions of the UK Court of Appeal (Blyth v Bloomsbury Health Authority, 1993; Gold v Haringey Health Authority, 1988).

The balance slowly started towards a more pro-patient approach from the erstwhile pro-doctor approach with two decisions of the Court of Appeal (Smith v Tunbridge Wells Health Authority, 1994; Pearce v United Bristol Healthcare NHS Trust, 1999).

The watershed moment in UK law relating to informed consent came when the House of Lords recognized the doctrine of informed consent in the landmark case of Chester $v$ Afshar. 4 This case accepted the primacy of the ethical principle of self-determination which forms the bedrock of individual or patient autonomy (Miola, 2007, p. 73). Holding that surgery performed without informed consent of the patient is unlawful, their Lordships declared that in modern law 'paternalism no longer rules' (Chester $v$ Afshar, 2004, ๆ 16 \& 18). In reaffirming that informed consent was a basic human right of a patient and that it protected the dignity and autonomy of the patient, the court held that the duty to inform the patient of risks was in itself a form of damage if it was not adhered to (Chester $v$ Afshar, 2004, 9 55). For the same reasons, proving causation and that an injury was caused due to failure of informing the patient about risks was irrelevant. The Chester decision cured an imbalance which existed in a doctor-patient relationship by providing a

${ }^{2}$ Courts in the UK had already held that a patient must be broadly informed about the risks associated with a particular medical procedure for the purpose of obtaining consent: Chatterton v Gerson [1981] QB 432.

${ }^{3}$ Although Lord Scarman showed a preference to the 'prudent patient' test that was also known as the doctrine of informed consent in the US.

4[2004] UKHL 41 (Lords Steyn, Hope and Walker delivered the majority opinion and Lords Bingham and Hoffman dissented). 
patient a right to receive information (Jones, 1999, p. 103). It is recognized that nowadays the dichotomy between the 'prudent patient' test and the 'reasonable/prudent doctor' test have vanished as professional organizations for medical practitioners themselves provide for informed consent to be taken by medical practitioners (Stauch, 2005, p. 66).

The Chester decision has been recently applied in a case where a doctor was held liable for failing to disclose comparative risk data for a particular procedure(Birch $\mathrm{v}$ University College London Hospital NHS Foundation Trust, 2008).

In Canadian law for example, under the doctrine of informed consent, the doctor has a duty to disclose all 'material' or 'unusual or special' risks. These risks are more or less such risks that the court feels would affect the mind of a patient when deciding whether or not to accept the treatment proposed (Lewis, 2006, p. 370). The doctrine of informed consent also includes a duty to answer questions and to inform the patient about alternative forms of treatment (Francis QC \& Johnstone, 2001, pp. 10-11).

It has also been argued that the doctor-patient relationship being a fiduciary relationship imposes a duty of disclosure on the doctors. This could be a new approach in looking at the doctrine of informed consent (Jackson, 2010, p. 210; Brazier, 1987; contrast with Kennedy, 1986, p. 138). It is thus clear that courts have played a critical role in the UK in adopting and applying the doctrine of informed consent. However, the Indian courts have not been so eager to do so.

\section{Development of Informed Consent in India}

\section{Judicial approach to 'informed consent'}

In India, the Supreme Court has given primacy to the Bolam principle of accepted medical practice in determining cases of medical negligence (Samira Kohli v Dr. Prabha Manchanda, 2008; Smt. Vinitha Ashok v Lakshmi Hospital and others, 2001; Achutrao Haribhau Khodwa and Others $v$ State of Maharashtra and Others, 1996; Indian Medical Association v V.P. Shantha and Others, 1995). 
In fact in the V.P. Shantha case, the Supreme Court had an occasion to remark whether the doctrine of informed consent could be applied in India at all and the Court said (Indian Medical Association $v$ V.P. Shantha and Others, 1995, p. 666):

38. In India, majority of citizens requiring medical care and treatment fall below the poverty line. Most of them are illiterate or semi-literate. They cannot comprehend medical terms, concepts, and treatment procedures. They cannot understand the functions of various organs or the effect of removal of such organs. They do not have access to effective but costly diagnostic procedures. Poor patients lying in the corridors of hospitals after admission for want of beds or patients waiting for days on the roadside for an admission or a mere examination, is a common sight. For them, any treatment with reference to rough and ready diagnosis based on their outward symptoms and doctor's experience or intuition is acceptable and welcome so long as it is free or cheap; and whatever the doctor decides as being in their interest, is usually unquestioningly accepted. They are a passive, ignorant and uninvolved in treatment procedures.

39. The poor and needy face a hostile medical environment inadequacy in the number of hospitals and beds, non-availability of adequate treatment facilities, utter lack of qualitative treatment, corruption, callousness and apathy. Many poor patients with serious ailments (e.g. heart patients and cancer patients) have to wait for months for their turn even for diagnosis, and due to limited treatment facilities, many die even before their turn comes for treatment. What choice do these poor patients have? Any treatment of whatever degree, is a boon or a favour, for them. The stark reality is that for a vast majority in the country, the concepts of informed consent or any form of consent, and choice in treatment, have no meaning or relevance. 
40. The position of doctors in government and charitable hospitals, who treat them, is also unenviable. They are overworked, understaffed, with little or no diagnostic or surgical facilities and limited choice of medicines and treatment procedures. They have to improvise with virtual non-existent facilities and limited dubious medicines. They are required to be committed, service oriented and non-commercial in outlook. What choice of treatment can these doctors give to the poor patients? What informed consent can they take from them?

It is clear that due to the constant reliance on the Bolam principle (as late as 2009 in Martin F. D'Souza v Mohd. Ishfaq, 2009), the position in India continues to be that which existed in the UK when the Sidaway decision was pronounced. The primary reason for the Supreme Court's paternalistic and protective attitude towards doctors and the medical profession seems to be due to the nature of polity and society in India. Owing to its largely poor, illiterate and ill-informed citizenry, it would be extremely onerous for law to place an obligation on the doctor to follow the doctrine of informed consent. Even if such an obligation were to be imposed, it would become nugatory as a patient would not be able to fully comprehend the risks and dangers associated with a particular medical procedure. However, as we may see, the Code of Medical Ethics Regulations does give limited recognition to the doctrine of implied consent.

The Supreme Court in Samira Kohli however notes that currently in India due to the ground realities only the Bolam and Sidaway principles are amenable but that the doctrine of informed consent (as recognized in Canterbury $v$ Spence in the US) would be the way to go if(Samira Kohli v Dr. Prabha Manchanda, 2008):

... [m]edical practitioners and private hospitals become more and more commercialized, and if there is a corresponding increase in the awareness of patient's rights among the public, inevitably, a day may come when we may have to move towards Canterbury. But not for the present. 


\section{Statutory framework:}

1. Indian Medical Council (Professional conduct, Etiquette and Ethics) Regulations, 2002 made under the Indian Medical council act, 1956 ("code of medical ethics regulations"):

The Code of Medical Ethics Regulations came into force on 11 March 2002 and are made by the Central Government under the Indian Medical Council Act, 1956 (Code of Ethics Regulations, 2002: power to make regulations prescribed in Section 20A read with Section 33(m) of the Indian Medical Council Act, 1956).

As stated, they relate to the "Professional Conduct, Etiquette and Ethics for registered medical practitioners" in India. Having statutory force, these regulations have a wide scope as they deal with the duties of physicians in general, physicians' duties to patients, physicians' duties in consultation, physicians' responsibilities to each other, physicians' duties to the public and the paramedics, unethical acts and professional misconduct. A method of punishment and disciplinary action for professional misconduct is also provided for in the Regulations.

Relevant to our discussion on informed consent is the last chapter in the Regulations which deals with 'Professional Misconduct' (Code of Ethics Regulations, 2002, Regulation 7). A physician is liable for disciplinary action for professional misconduct for any commission or omission envisaged in the Regulations - there are 24 such instances. At least three of these instances refer to a requirement of obtaining consent or informed consent. They are:

7.16 Before performing an operation the physician should obtain in writing the consent from the husband or wife, parent or guardian in the case of minor, or the patient himself as the case may be. In an operation which may result in sterility the consent of both husband and wife is needed...

7.21 No act of invitro fertilization or artificial insemination shall be undertaken without the informed consent of the female patient and her spouse as well as the donor. Such consent shall be obtained in writing only after the patient is provided, at her 
own level of comprehension, with sufficient information about the purpose, methods, risks, inconveniences, disappointments of the procedure and possible risks and hazards.

7.22 Research: Clinical drug trials or other research involving patients or volunteers as per the guidelines of ICMR can be undertaken, provided ethical considerations are borne in mind. Violation of existing ICMR guidelines in this regard shall constitute misconduct. Consent taken from the patient for trial of drug or therapy which is not as per the guidelines shall also be construed as misconduct.... (Emphasis supplied)

The first situation where written consent of a patient or his kin is required is where an operation will be performed by the physician. The second, and the only statutory recognition for the doctrine of informed consent in India, is where informed consent must be obtained in an IVF (in-vitro fertilization) or artificial insemination procedure from a female patient, her spouse and the donor of the semen. Finally, consent is necessary for clinical drug trials or therapy according to the Indian Council for Medical Research Guidelines in that regard (ICMR Ethical Guidelines for Biomedical Research on Human Participants, 2006).

It is evident that the constituents of informed consent in IVF/artificial insemination procedures are actually spelt out in the regulation. These cumulative constituents are:

1. Informed Consent must be obtained in writing;

2. It must be obtained after providing the patient sufficient information about the purpose, methods, risks, hazards, inconveniences, disappointments of the procedure; and

3. Such information must be provided at the patient's own level of comprehension.

Failure to obtain informed consent in an IVF procedure exposes a medical practitioner to disciplinary action under the Regulations (Code of Ethics Regulations, 2002, Regulation 8). A complaint in 
this regard can be made by any person to the Medical Council of India or the respective State Medical Council and there is no restriction on who can lodge this complaint. After receiving the complaint, the Council can enquire into the alleged professional misconduct, in this case failure to obtain informed consent, and give a hearing to the accused practitioner. If a physician is found to be guilty, then the Council has power to take any necessary steps in punishing him/her, as well as deleting the name of the physician from the list of registered practitioners authorised to practice medicine. In the interim, before a decision of guilt is made, a physician can also be circumscribed from performing any medical procedure or practice under scrutiny.

Being the only recognition of the doctrine of informed consent, it is clear that due to its limited applicability (to IVF procedures) it is insufficient to ensure that the aims of informed consent are achieved in medical practice and care in India. Also, failure to obtain informed consent exposes a physician or other medical professional to liability in negligence. The Code of Medical Ethics Regulations, to that effect, provide for a feeble remedy, where only the practitioner is punished but the victim does not get any redress for the injury caused to him/her.

It is necessary to point out that if informed consent cannot be generally applicable in medical negligence claims, why is it that the Code of Medical Ethics Regulations makes informed consent mandatory for IVF/artificial insemination procedures. Is this a pointed to the fact that such procedures are generally opted by people who are relatively well-off than the other sections of the society? Are these people necessarily more educated and informed to be able to make a rational choice when presented with the risks and dangers of a treatment?

Alternatively, what level of informed consent can be made applicable in India? The answer to that question is complex for two reasons. One, there is a serious dichotomy in the nature of medical facilities that are available in urban and rural settings in India. While, patient autonomy is integral to every human being irrespective of their economic or social standing, the doctor can be given some discretion to decide how much information about risks can be disclosed in different settings. Here, the communicative role 
of a doctor becomes important. He must understand the perception and the context in which a patient looks at the risk and then disclose the same. However, this reinforces the 'reasonable doctor' test which has been discarded in the UK since Chester. Secondly, if the doctor is given the discretion to decide the 'best interest' of the patients in a country like India that may also lead to misuse which the principles behind informed consent militate against.

\section{Transplantation of Human Organs Act, 1994}

When a person decides to donate his/her organ under the Transplantation of Human Organs Act, 1994, the Authority under the Act is under an obligation to inform the donor of the possible outcomes and postoperative changes after the transplant surgery. Lack of informed consent in such cases will vitiate the entire process(Pawan Anand and another v Director General of Health Services and others, 2012).

\section{Consumer Protection Act, 1986}

The Consumer Protection Act ('CPA') has also been invoked in many cases of medical negligence since the Supreme Court in V.P. Shantha permitted the same (Indian Medical Association $v$ V.P. Shantha and Others, 1995). In various cases under the CPA, the consumer forums and commissions have held doctors to be negligent for failure to obtain informed consent (Dr. AK Mittal $\mathcal{E}$ Anr v. Rajkumar \& Another, 2009; H.S. Tuli v Post Graduate Institute of Medical and others, 2008; Saroj Chandoke and others v Sri Ganga Hospital and others, 2007).

\section{Conclusion}

It is clear that unlike many other fields of law where Indian law mirrors the changes in the UK, in the case of doctrine of informed consent, the current economic and societal problems do not permit us to apply a liberated doctrine of informed consent in India.

However, the forward-thinking ruling of the House of Lords in Chester cannot be sidelined. The question eventually boils down to whether medical ethics should follow the law or vice-versa. In Sidawayand Chester both the courts held that law should be in the driver's seat. In India, there is no reason why this should not be the 
case. Additionally, informed consent has already been recognized in the Code of Medical Ethics which points to the fact that there is a readiness in the people of India and more importantly the medical profession to assume a greater responsibility in disclosure of material risks before performing medical procedures. The way forward would be to recognize this and to implement it in other areas of medical practice and only then will the principles of bodily autonomy and self-determination be of value to Indians. This role is primarily of the courts in India and by only recognizing this can the courts bring about any substantial social changes, especially in promoting patient rights

\section{Reference}

Achutrao Haribhau Khodwa and Others v State of Maharashtra and Others, (1996) 2 SCC 634 (Supreme Court of India 1996).

Airedale NHS Trust v Bland, [1993] AC 789 (House of Lords 1993).

Birch v University College London Hospital NHS Foundation Trust, [2008] EWHC 2237 (Court of Appeal 2008).

Blyth v Bloomsbury Health Authority, [1993] 4 MedLR 151 (Court of Appeal 1993).

Bolam v Friern Hospital Management Committee, [1957] 1 WLR 582 (House of Lords 1957).

Brazier, M. (1987). Patient autonomy and consent to treatment: The role of the law? Journal of Legal Studies, 7, 169-193.

Cane, P., \& Conaghan, J. (Eds.). (2008). The new Oxford companion to law. 202. Oxford: Oxford University Press.

Chester v Afshar, [2005] 1 AC 134 (House of Lords 2004).

Code of Ethics Regulations, 2002. (2010). Retrieved August 19, 2012, from Medical Council of India: http://www.mciindia.org/ RulesandRegulations/CodeofMedicalEthicsRegulations2002.aspx

Dr. A. K. Mittal \& Anr v. Rajkumar \& Anr, 2009 Indlaw NCDRC 37 (National Consumer Disputes Redressal Commission 2009).

Eyal, N. (2012). Informed Consent. Retrieved August 15, 2012, from The Stanford Encyclopedia of Philosophy: http://plato.stanford.edu/ archives/fall2012/entries/informed-consent/ 
Francis Q. C. R., \& Johnstone, C. (2001). Medical Treatment: Decisions and the Law. Butterworths.

Gold v Haringey Health Authority, [1988] QB 481 (Court of Appeal 1988).

Grubb, A., Liang, J., \& McHale, J. (2010). Principles of medical law. Oxford University Press.

Grubb, A., Liang, J., \& McHale, J. (2010). Principles of medical law. Oxford University Press.

H. S. Tuli v Post Graduate Institute of Medical and Others, 2008 Indlaw NCDRC 58 (National Consumer Disputes Redressal Commission 2008).

ICMR Ethical Guidelines for Biomedical Research on Human Participants, 2006. (n.d.). Retrieved August 20, 2012, from Indian Council for Medical Resarch: http://icmr.nic.in/ethical_guidelines.pdf

Indian Medical Association v V. P. Shantha and Others, (1995) 6 SCC 651 (Supreme Court of India 1995).

Jackson, E. (2010). Medical law: Text, cases and materials. Oxford: Oxford University Press.

Jones, M. (1999). Informed consent and other fairy stories. Medical Law Review, 7, 103.

Kennedy, I. (1986). The Fiduciary Relationship and its Application to Doctors. In P. Birks (Ed.), Wrongs and remedies in the twenty-first century (p. 138). Clarendon Press.

Kennedy, I. (n.d.).

Lewis, C. (2006). Clinical negligence: A practical guide (6th ed.). Tottel Publishing.

Manson, N., \& O'Neill, O. (2007). Rethinking informed consent in bioethics. Cambridge: Cambridge University Press.

Martin F. D'Souza v Mohd. Ishfaq, (2009) 3 SCC 1 (Supreme Court of India 2009).

Miola, J. (2007). Medical ethics and medical law: A symbiotic relationship. Portland: Hart Publishing.

O'Neill, O. (2003). Symposium on consent and confidentiality: Some limits of informed consent. Journal of Medical Ethics, 29(1), 4-7.

Pattinson, S. (2006). Medical law and ethics (1st ed.). Sweet \& Maxwell. 
Pawan Anand and another v Director General of Health Services and others, 2012 Indlaw Del 1360 (Delhi High Court 2012).

Pearce v United Bristol Healthcare NHS Trust, [1999] PIQR 53 (1999).

Re F (Mental Patient: Sterilization), [1990] 2 AC 1 (House of Lords).

Samira Kohli v Dr. Prabha Manchanda, (2008) 2 SCC 1 (Supreme Court of India 2008).

Saroj Chandoke and others v Sri Ganga Hospital and others, 2007 Indlaw NCDRC 46 (National Consumer Disputes Redressal Commission 2007).

Schloendorff v Society of New York Hospital, (1914) 211 NY 125 (New York Court of Appeals 1914).

Schuck, P. H. (1994). Rethinking informed consent. Yale Law Journal, 103, 906.

Schuck, P. H. (1994). Rethinking informed consent. Yale Law Journal, 103, 903.

Schuck, P. H. (1994). Rethinking informed consent. Yale Law Journal, 103, 903.

Sidaway v Board of Governors of the Bethlem Royal Hospital and the Maudsley Hospital and others, [1985] AC 871 (House of Lords 1985).

Smith v Tunbridge Wells Health Authority, [1994] 5 MedLR 334 (Court of Appeal 1994).

Smt. Vinitha Ashok v Lakshmi Hospital and others, (2001) 8 SCC 731 (Supreme Court of India 2001).

Stauch, M. (2005). Causation and confusion in respect of medical nondisclosure: Chester v. Afshar. Nottingham Law Journal, 14, 66.

Stauch, M., Wheat, K., \& Tingle, J. (2006). Text, cases and materials on medical law (3rd ed.). Routledge Cavendish. 